EESTI NSV TEADUSTE AKADEEMIA TOIMETISED. 20. KÖIDE KEEMIA * GEOLOOGIA, 197.1, NR. I

ИЗВЕСТИЯ АКАДЕМИИ НАУК ЭСТОНСКОИ ССР. ТОМ 20 ХИМИЯ * ГЕОЛОГИя. 1971, № 1

\title{
ОТДЕЛЕНИЕ КАРБОНАТОВ ОТ ФОСФАТНОГО ВЕЩЕСТВА ФОСФОРИТОВ МЕТОДОМ ИЗБИРАТЕЛЬНОГО РАСТВОРЕНИЯ
}

По данным химических анализов, почти все фосфориты содержат помимо составных частей минерала фторапатита $\left(\mathrm{CaO}, \mathrm{P}_{2} \mathrm{O}_{5}\right.$ и $\left.\mathrm{F}\right)$ еще и $\mathrm{CO}_{2}$. Вопрос о связях последней оставался долгое время спорным [1, ${ }^{1}$ ]. В общем случае, по мнению группы исследователей, часть $\mathrm{CO}_{2}$ входит в состав фосфатного вещества фосфоритов (фторкарбонатапатита), а часть связана в карбонатах. По мнению других авторов, вся $\mathrm{CO}_{2}$ связана в карбонатах, из которых часть находится в тонкодиспергированном виде в фосфатных частицах, составленных фторапатитом. Обыкновенными химическими методами определяется общее содержание $\mathrm{CO}_{2}$, и поэтому результаты не могут быть использованы для разрешения вопроса ее связей. Изготовление очищенных проб фосфатного вещества трудоемко, и полученные продукты недостаточно очищаются для точного определения его состава.

Для количественного определения различных форм углекислоты в фосфоритах Сильверман и др. разработали метод избирательного растворения с применением полумолярного водного раствора триаммонийцитрата [3]. По их данным, растворимость кальцита в указанном реагенте превышает растворимость фторкарбонатапатита примерно в 50 раз и составляет на 100 мл реагента соответственно 0,660 и 0,012 г. В результате ими установлено, что количество кальцита, которое может быть обнаружено этим методом, составляет $0,1 \%$, что во много раз превышает возможности рентгенографического и термического методов.

По методике, описанной в [3], для анализа берут 1 2 фосфорита, измельченного до - 200 меш, смешивают в колбе со 100 мл реагента и оставляют при комнатной температуре на 24 , временами встряхивая. Затем нерастворимый остаток отфильтровывается, промывается водой, высушивается и анализируется на содержание $\mathrm{CO}_{2}$. Полученный результат принимается за содержание $\mathrm{CO}_{2}$, связанной в фосфатном минерале фосфорита. По другому варианту определяется в фильтрате $\mathrm{CaO}$, а по результату анализа вычисляется количество $\mathrm{CO}_{2}$, связанной в кальците.

Разработанная методика впоследствии была использована для анализа зарубежных фосфоритов [4], а также фосфоритов СССР $\left[{ }^{5,6}\right]$.

Применяя эту методику, Дюшатель указывает [7], что измельчение фосфорита свыше 100 меш приводит к частичному растворению фосфата и поэтому следует это избегать. По его данным, доломит в условиях анализа, предположенных в [3], практически не растворяется. Смит и Лехр [8] с целью более полного извлечения из раствора кальцита и доломита внесли изменение в эту методику: предложили обрабатывать фос- 
ปี

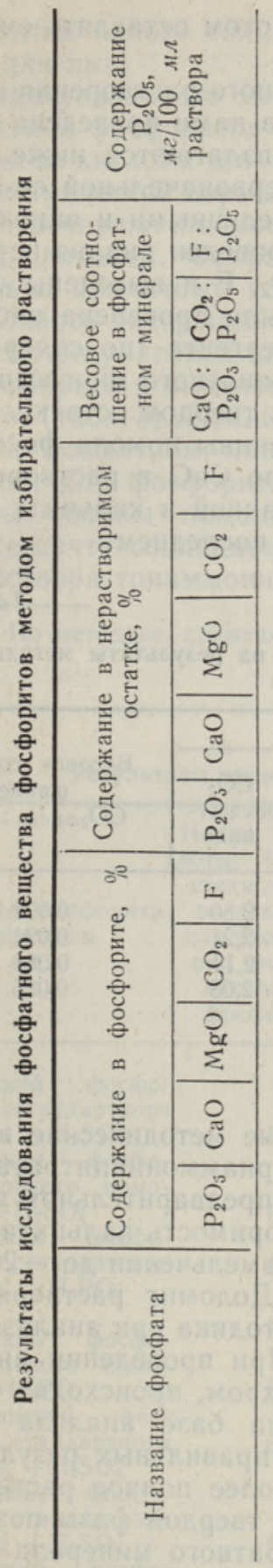

$\mid \underset{\infty}{\infty}$

I:

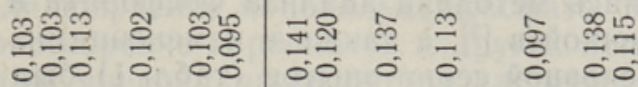

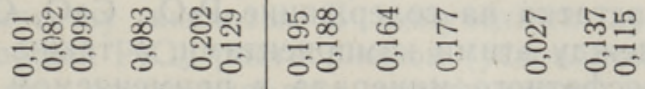

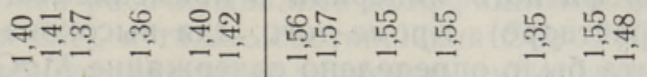

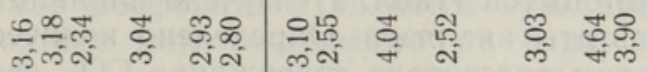

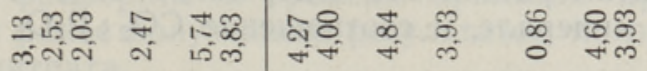

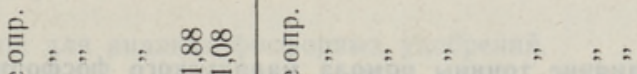

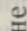

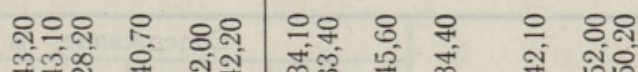

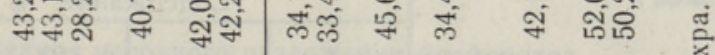

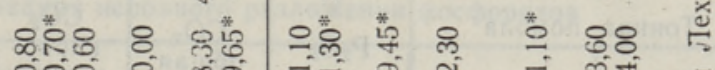

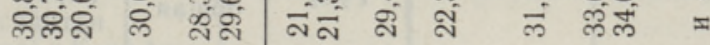
ป⿻

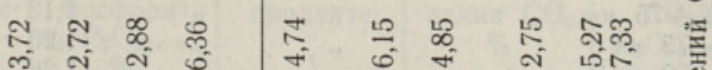
药

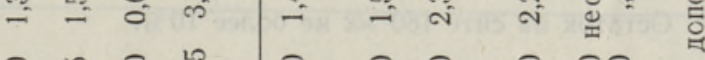

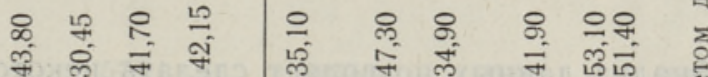

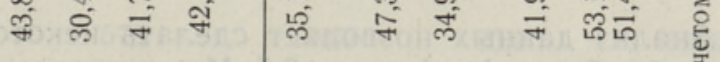
으 ㅇำ เ

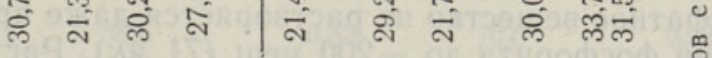

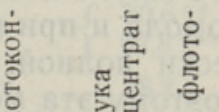
อ.

莌

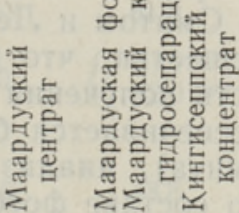

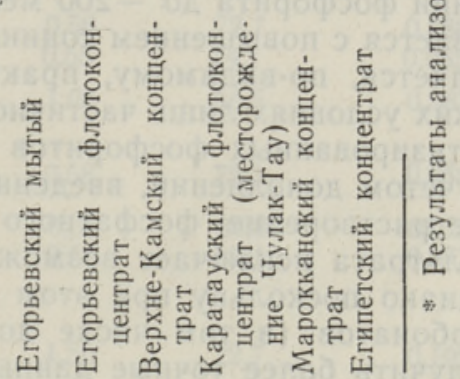


форит реагентом 4 при температуре $65^{\circ} \mathrm{C}$, а потом оставлять смесь на 18 ч при комнатной температуре.

Для проверки указанного метода избирательного растворения и уточнения состава фосфатного вещества фосфоритов нами проведено дополнительное исследование, результаты которого излагаются ниже. Нами применялась методика анализа фосфорита в первоначальной ее форме, предложенной в [3], а также с изменениями, введенными и описанными в $\left.{ }^{8}\right]$. В основной серии опытов (табл. 1) был проведен анализ нерастворимого остатка на содержание $\mathrm{P}_{2} \mathrm{O}_{5}, \mathrm{CaO}, \mathrm{CO}_{2}, \mathrm{~F}$ и выведены соотношения между этими компонентами, а также была проверена растворимость фосфатного минерала в применяемом реагенте (по содержанию $\mathrm{P}_{2} \mathrm{O}_{5}$ в растворе). Кроме того, для высококарбонатного кингисеппского фосфорита было определено содержание $\mathrm{MgO}$ в твердом остатке. В другой серии опытов (табл. 2) изучено влияние тонины помола фосфорита на результаты анализов. Определено количество $\mathrm{CaO}$ в растворе, а по результатам рассчитано содержание $\mathrm{CO}_{2}$, связанной в кальците и фосфатном минерале, и соотношение $\mathrm{CO}_{2}: \mathrm{P}_{2} \mathrm{O}_{5}$ в последнем.

Таблица 2

Влияние тонины помола маардуского фосфорита на результаты метода избирательного растворения

\begin{tabular}{|c|c|c|c|c|c|}
\hline \multirow[b]{2}{*}{ Тонина помола } & \multicolumn{4}{|c|}{ Содержание, \% } & \multirow[b]{2}{*}{$\begin{array}{c}\text { Весовое соотно- } \\
\text { шение } \\
\mathrm{CO}_{2 \text { фасф. }: \mathrm{P}_{2} \mathrm{O}_{5}}\end{array}$} \\
\hline & $\mathrm{P}_{2} \mathrm{O}_{5}$ & $\begin{array}{c}\mathrm{CO}_{2} \\
\text { общая }\end{array}$ & $\begin{array}{c}\mathrm{CO}_{2} \\
\text { карбо- } \\
\text { натная }\end{array}$ & $\begin{array}{c}\mathrm{CO}_{2} \\
\text { фосфат- } \\
\text { ная }\end{array}$ & \\
\hline $\begin{array}{c}\text { Стандартный помол * } \\
18,8 \%+75 \text { мк } \\
-75 \text { мк } \\
-50 \text { мк }\end{array}$ & $\begin{array}{c}24,36 \\
" n \\
" \\
"\end{array}$ & $\begin{array}{l}3,34 \\
" \\
, \\
"\end{array}$ & $\begin{array}{l}1,04 \\
1,13 \\
1,20 \\
1,26\end{array}$ & $\begin{array}{l}2,30 \\
2,21 \\
2,14 \\
2,08\end{array}$ & $\begin{array}{l}0,094 \\
0,091 \\
0,088 \\
0,085\end{array}$ \\
\hline
\end{tabular}

* Остаток на сите 180 мк не более $10 \%$.

Анализ данных позволяет сделать некоторые методические выводы. При обработке фосфорита $0,5 M$ раствором триаммонийцитрата, по [ ${ }^{3}$, фосфатное вещество не растворяется даже при предварительном измельчении фосфорита до -200 меш $(71 \mu \kappa)$. Растворимость кальцита увеличивается с повышением тонины помола и при измельчении до -200 меш является, по-видимому, практически полной. Доломит растворяется в таких условиях лишь частично. Поэтому эта методика при анализе доломитизированных фосфоритов не применима. При проведении анализов с учетом дополнений, введенных Смитом и Лехром, происходит частичное растворение фосфатного вещества, что на базе анализа только фильтрата исключает возможность получения правильных результатов. Однако поскольку при этом обєспечивается более полное растворение карбонатов (в том числе доломита), анализ твердой фазы позволяет получить более точные данные о составе фосфатного минерала фосфорита. При высоком содержании доломита и в этом случае могут быть получены несколько завышенные результаты по содержанию $\mathrm{CO}_{2}$ в фосфатном минерале.

Данные исследования показывают, что часть $\mathrm{CO}_{2}$ во всех изученных фосфоритах входит в состав фосфатного минерала. О̄тбрасывая данные, полученные для высококарбонатных фосфоритов методом, описанным в [3], видно, что соотношения между компонентами фосфатного вещества 
фосфоритов одного типа колеблются в небольших пределах и характерны для них.

Кроме указанного метода нами испытано в этих же целях неполное разложение фосфоритов серной и фосфорной кислотами. В этих опытах количество кислоты для разложения фосфорита составляло $40-60 \%$ от стехиометрической нормы для получения монокальцийфосфата. Эти условия обеспечивают полное растворение карбонатов и других легкоразлагаемых примесей. Фосфатный минерал растворяется частично, пропорционально принятому количеству кислоты. В полученных продуктах определялось содержание общей $\mathrm{P}_{2} \mathrm{O}_{5}$, растворяемой (усвояемой) $\mathrm{P}_{2} \mathrm{O}_{5}$ * и $\mathrm{CO}_{2}$, по результатам анализа рассчитывались коэффициенты разложения фосфорита и выделения $\mathrm{CO}_{2}$, а также соотношение $\mathrm{CO}_{2}: \mathrm{P}_{2} \mathrm{O}_{5}$ неусв. в продукте (табл. 3). Последнее соответствует значению соотношения $\mathrm{CO}_{2}$ : : $\mathrm{P}_{2} \mathrm{O}_{5}$ в фосфатном минерале фосфорита и является практически постоянным для фосфорита одного типа независимо от вида и нормы кислоты, тонины помола фосфорита и времени хранения продукта, а также почти совпадает с ранее полученным результатом по применению раствора триаммонийцитрата.

* По методике, применяемой для анализа фосфорных удобрений.

Таблица 3

Результаты исследованця неполного разложения фосфоритов

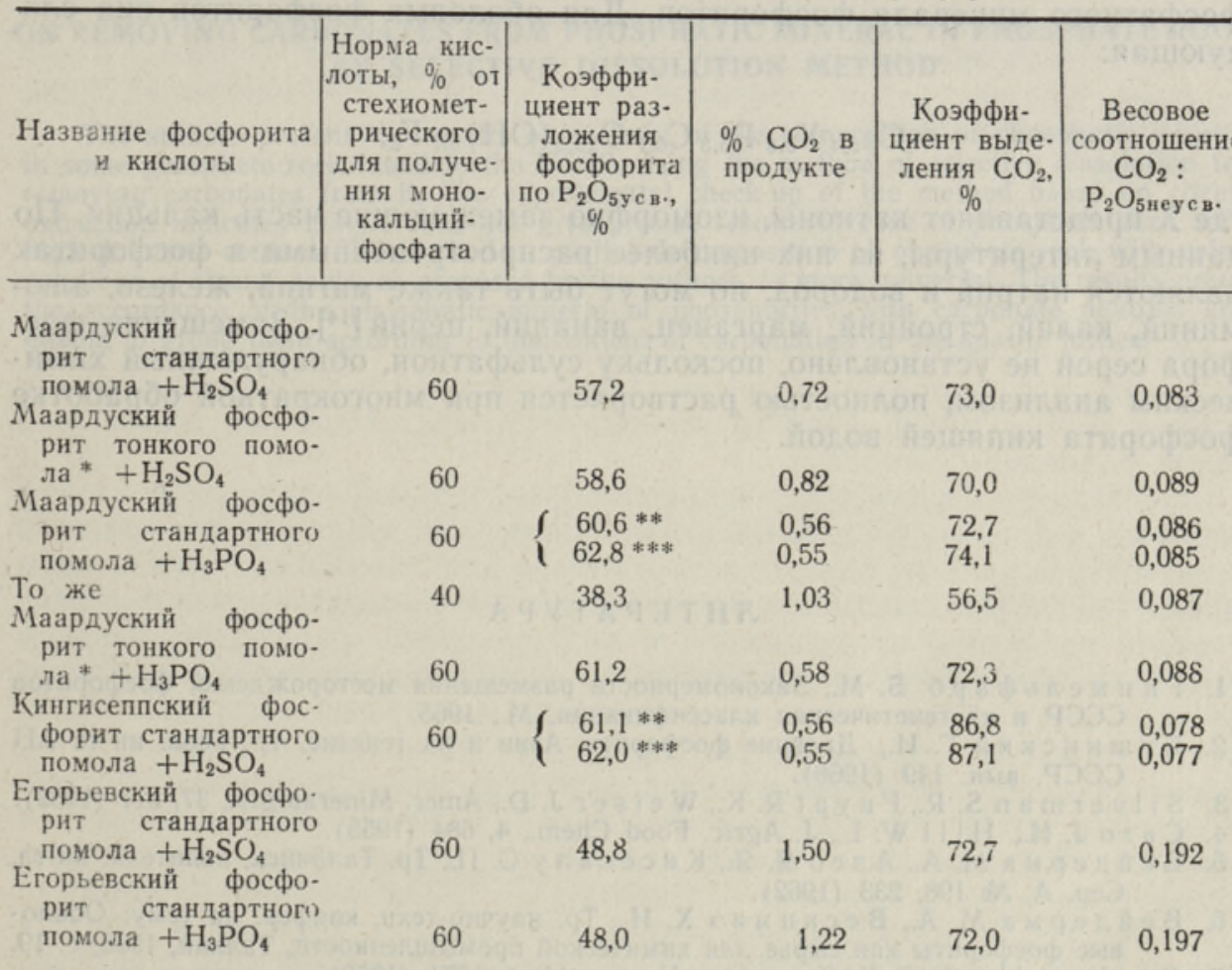

* Остаток на сите 180 мк 2,9\%, проходит сито 70 мк 57,9\%.

** Через сутки после изготовления.

*** Через 10 суток после изготовления. 
Постоянство состава фосфатного минерала, полученное различными способами в разных образцах фосфорита одного типа, не может быть объяснено наличием $\mathrm{CO}_{2}$ в виде тонкораспределенного кальцита и является доказательством реального существования фторкарбонатапатита как основы фосфатного вещества фосфоритов. С учетом вышесказанного наиболее вероятное весовое соотношение $\mathrm{CO}_{2}: \mathrm{P}_{2} \mathrm{O}_{5}$ в фосфатном минерале оболовых фосфоритов (Маардуского, Кингисеппского и др. месторождений) составляет $0,08-0,09$, у желваковых фосфоритов русской платформы $0,17-0,19$. Весовое соотношение $\mathrm{CaO}: \mathrm{P}_{2} \mathrm{O}_{5}$ в нем составляет в среднем соответственно 1,40 и 1,55 , соотношение $\mathrm{F}: \mathrm{P}_{2} \mathrm{O}_{5}-0,10$ н $0,12-0,14$. Полученные данные подтверждают высказывания о близости состава фосфатного минерала оболовых фосфоритов к минералу франколит, желваковых фосфоритов - к минералу курскит (по классификации Бушинского) [ $\left.{ }^{5,9-12}\right]$. Наиболее низкие соотношения $\mathrm{CaO}: \mathrm{P}_{2} \mathrm{O}_{5}$ и $\mathrm{CO}_{2}: \mathrm{P}_{2} \mathrm{O}_{5}$ получены в фосфатном минерале каратауских фосфоритов. Полученное соотношение $\mathrm{CO}_{2}: \mathrm{P}_{2} \mathrm{O}_{5}$ в имеющейся пробе марокканского фосфорита $(0,14)$ совпадает с ранее приведенным в литературе [ $\left.{ }^{8}\right]$.

Как известно, в последние годы с применением методов ИК-спектроскопии, рентгенографии, термогравиметрии и др. получены новые доказательства о вхождении $\mathrm{CO}_{2}$ в фосфатное вещество фосфоритов $\left[{ }^{13}\right]$. Bce же, метод избирательного растворения является наиболее доступным и позволяет установить количественные соотношения между компонентами фосфатного минерала.

По полученным данным возможно примерно определить формулу фосфатного минерала фосфоритов. Для оболовых фосфоритов она следующая:

$$
\mathrm{Ca}_{9,4} \mathrm{X}_{0,6} \mathrm{P}_{5,3} \mathrm{C}_{0,7} \mathrm{O}_{23,3}(\mathrm{OH})_{0,7} \mathrm{~F}_{2}
$$

где X представляет катионы, изоморфно замещающие часть кальция. По данным литературы, из них наиболее распространенными в фосфоритах являются натрий и водород, но могут быть также магний, железо, алюминий, калий, стронций, марганец, ванадий, церий $\left[{ }^{14}\right]$. Замещения фосфора серой не установлено, поскольку сульфатион, обнаруженный химическим анализом, полностью растворяется при многократной обработке фосфорита кипящей водой.

\section{ЛИ Т Е Р А Т Р А}

1. Ги м м ельф ар б Б. М., Закономерности размещения месторождений фосфоритов СССР и их генетическая классификация, М., 1965.

2. Бу ши нски й Г. И., Древние фосфориты Азии и их генезис. Тр. Геол. ин-та АН СССР, вып. 149 (1966).

3. S i l verm a n S. R., F u y a t R. K., W e is e r J. D., Amer. Mineralogist, 37, 211 (1952).

4. Caro J. H., Hill W. L., J. Agric. Food Chem., 4, 684 (1955).

5. В е й де р м а М. А., А н со Я. Я., К а с ес ал у С. П., Тр. Таллинск, политехн. ин-та, Cep. A, № 198, 233 (1962).

6. В ей де р м а М. А., В е ским я э Х. И., Тр. научно-техн, конфер. на тему: Оболовые фосфориты как сырье для химической промышленности, Таллин, 1968 , с. 19.

7. Du ch a teli e G., Bull. Soc., chim. France. $N^{\circ} 4,1671$ (1968).

8. Smith J. P., Lehr J. P., Agric. Food Chem., 14, 342 (1966).

9. Бушин с кий Г. И., Апатит, фосфорит, вивианит, М., 1952.

10. Бушин ски й Г. И., Вопросы геологии агрономических руд, М., 1956, с. 49.

11. Бу шин с ки й Г. И., Фосфатные породы. В кн.: Справочное руководство по петрографии осадочных пород, М., 1958. 
12. Л о г А., Изв. АН ЭССР, Сер. физ.-матем. и техн. наук, 11, № 3, 229 (1962).

13. Специальное приложение к Bull. Soc. chim. France, $\mathrm{N}^{\circ} 4$ (1968).

14. С м и р о в А. И., В кн.: Физические методы исследования минералов осадочных пород, М., 1966, с. 260.

таллинский политехнический институт Поступила в редакцию 23/IV 1970

M. VEIDERMA, HELGI VESKIMAE

\section{KARBONAATIDE ERALDAMISEST FOSFORIIDI FOSFAATSEST AINEST SELEKTIIVSE LAHUSTAMISE MEETODIL}

Esitatakse andmed NSV Liidu mõnede fosforiitide fosfaatse aine koostise kohta, kasutades selle karbonaatidest eraldamiseks selektiivse lahustamise meetodit. Senise, triammooniumtsitraadi lahust kasutava meetodi eksperimentaalne kontroll näitas, et tema abil dolomiidirikaste fosforiitide kohta saadud andmed on ebatäpsed. Universaalsen on autorite poolt kasutatud meetod, mille järgi fosforiit tugevate hapete abil osaliselt lagundatakse. Analüüsi tulemused kinnitasid fosforiitide fosfaatse aine vastavust fluorkarbonaatapatiidile ja vōimaldasid neid täpsemalt rühmitada apatiidi molekulisse kuuluva karbonaatiooni hulga järgi.

\section{VEIDERMA, HELGI VESKIMÄE}

\section{ON REMOVING CARBONATES FROM PHOSPHATIC MINERAL IN PHOSPHATE ROCK BY SELECTIVE DISSOLUTION METHOD}

The authors present the results of a study of the composition of phosphatic mineral in some phosphate rock found in the USSR, using the method of selective dissolution for $\tau \in$ moving carbonates from it. The experimental check-up of the method based on citrate extraction indicates that it does not give precise results in case of phosphate rock with high dolomite content. The method of partial decomposition of phosphate rock with using solutions of strong acids, as proposed by the authors, is more universal. The results prove the accordance of the phosphatic mineral of phosphorites with carbonate apatites and enable to group them according to the content of carbonation in the apatite lattice. 